\title{
A gestão de resíduos sólidos urbanos e o desenvolvimento sustentável: uma revisão
}

É notório que com passar dos últimos séculos a sociedade desenvolveu-se e evoluiu sobremaneira em suas atividades cotidianas, desde as mais básicas até as mais complexas, com ressalto para o aumento da produtividade em diversos setores. Contudo, pouco se pensou que a maior produção de bens geraria consigo ampla quantidade diária de resíduos. O ciclo de vida dos resíduos é marcado por ter um término problemático, com sobressalto para as consequências danosas ao meio ambiente. Diante deste cenário, este estudo objetivou buscar evidências na literatura científica para reunir e sintetizar o conhecimento produzido sobre a importância da gestão dos resíduos sólidos tendo em vista o desenvolvimento sustentável. Para tanto, foi realizado em março de 2020, levantamento da literatura pertinente ao assunto nas bases de dados Periódicos CAPES e Google Acadêmico. Os descritores utilizados foram: 'Gestão de Resíduos' AND 'Indicadores de Sustentabilidade' AND 'Desenvolvimento Sustentável', e 'Waste Management' AND 'Sustainability Indicators' AND 'Sustainable Development', sendo obtidos quatro artigos para comporem o presente estudo. Como resultado, foi possível observar que a gestão de resíduos sólidos no Brasil ainda está em fase limitada de desenvolvimento, acarretando em vultosos impactos ao meio ambiente. Ademais, os artigos analisados evidenciam que a gestão de resíduos sólidos em nosso país ainda demanda apoio das esferas governamentais, no âmbito legal para a criação de políticas públicas, e da sociedade nas condutas e práticas culturais cotidianas.

\section{Urban solid waste management and sustainable development: a review}

It is well known that over the past few centuries, society has developed and evolved greatly in its daily activities, from the most basic to the most complex, with emphasis on increasing productivity in various sectors. However, little was thought that the greater production of goods would generate a large daily amount of waste. The waste life cycle is marked by having a problematic ending, with a start for the harmful consequences to the environment. Given this scenario, this study aimed to seek evidence in the scientific literature to gather and synthesize the knowledge produced on the importance of solid waste management in view of sustainable development. To this end, in March 2020, a survey of relevant literature was carried out in the CAPES and Google Scholar databases. The descriptors used were: 'Waste Management' AND 'Sustainability Indicators' AND 'Sustainable Development', and 'Waste Management' AND 'Sustainability Indicators' AND 'Sustainable Development', obtaining four articles to compose the present study. As a result, it was possible to observe that the management of solid waste in Brazil is still in a limited stage of development, causing significant impacts on the environment. Furthermore, the articles analyzed show that the management of solid waste in our country still requires support from governmental spheres, within the legal framework for the creation of public policies, and from society in daily cultural conduct and practices.

Keywords: Waste Management; Sustainable development; Sustainability Indicators.

Topic: Desenvolvimento, Sustentabilidade e Meio Ambiente

Reviewed anonymously in the process of blind peer.
Received: $12 / 12 / 2019$

Approved: $20 / 03 / 2020$

Luciana Íris Amaro Nogueira (iD

Faculdade Integrada de Patos, Brasil

http://lattes.cnpq.br/0485924830569360

http://orcid.org/0000-0002-0265-4708

ciana_amaro@hotmail.com

Islane Cristina Martins (iD)

Universidade Federal de Pernambuco, Brasil

http://lattes.cnpq.br/0688414232610524

http://orcid.org/0000-0003-2351-2730

relacionamento@passenomestrado.com

Georgia Rolim da Silva

Faculdade Integrada de Patos, Brasil

http://lattes.cnpq.br/7489929699341169

http://orcid.org/0000-0002-2346-281X

rolimgeorgia08@gmail.com

\section{Referencing this:}

NOGUEIRA, L. I. A.; MARTINS, I. C.; MIRANDA, G. R. S.. A gestão de resíduos sólidos urbanos e o desenvolvimento sustentável: uma revisão. Environmental Scientiae, v.2, n.1, p.48-57, 2020. DOI: 


\section{INTRODUÇÃO}

De acordo com o Conselho Nacional do Meio Ambiente (CONAMA), os resíduos sólidos são rejeitos em estado sólido e semissólido que resultam de atividades de origem industrial, doméstica, hospitalar, comercial, agrícola, de serviços e de varrição. Tal conceito é apresentado pelo Ministério do Meio Ambiente (CONAMA, 1993) e tem vigência em todo o território brasileiro.

Conforme a referida definição, salienta-se que os resíduos sólidos são subdivididos conforme suas especificidades, a exemplo dos Resíduos Industriais, Resíduos Hospitalares, Resíduos de Construção Civil, Resíduos Nucleares, entre outros. Com relação aos Resíduos Sólidos Urbanos (RSU), foco da análise deste estudo, eles são definidos como sendo materiais indesejáveis para quem fez ou pretende descartá-los, podendo ter origem diversificada, evidente potencial de resultar em danos à saúde e à qualidade de vida das pessoas e ambientes, caso sejam descartados em local impróprio (SILVA, 2017).

Diante do crescimento progressivo da produção de diversos setores e do consequente aumento do descarte de Resíduos Sólidos Urbanos, esta relação tem se mostrado como um dos maiores problemas relativos ao meio ambiental, uma vez que o descarte culmina, na maioria das vezes, em acúmulo e destino final inadequado dos resíduos. Conforme Sousa (2019), o fato é que a concentração de dejetos sólidos e o desfecho final deles é um tema de crescente preocupação na esfera governamental, empresarial e da sociedade civil em diversos países do mundo.

É com base no referido cenário, marcadamente evidente no Brasil, que este estudo tem como objetivo norteador buscar evidências na literatura científica pertinente a respeito do conhecimento produzido sobre a importância da gestão dos resíduos sólidos, tendo em vista o desenvolvimento sustentável. Assim, este artigo coloca em questão a discussão sobre os princípios de sustentabilidade para uma gestão mais efetiva dos resíduos sólidos urbanos.

É importante destacar que a busca por diretrizes legais com vistas para o estabelecimento de procedimentos para o descarte de RSU que tenham como foco reduzir os impactos causados ao meio ambiente, de modo que possam ser seguidos em todo o território nacional, e que contemplem as premissas basilares do desenvolvimento sustentável. Neste contexto, a Política Nacional de Resíduos Sólidos é apresentada como fundamental para articular as três esferas de gestão (União, Estados e Municípios), em ações conjuntas com os setores produtivos e da sociedade civil, em prol de soluções para os problemas causados pelos resíduos, que comprometem a qualidade de vida dos brasileiros.

Tal delimitação de tema faz-se de suma relevância, uma vez que os indícios de mercado apontam para a manutenção no crescimento da produção de produtos, o que acaba refletindo, como numa espécie de cadeia, no maior consumo e consequente descarte.

\section{REVISÃO TEÓRICA}

A gestão dos resíduos sólidos no Brasil é gerida pela Lei no 12.305, de 2010, que instituiu a Política Nacional de Resíduos Sólidos (PNRS), sendo a responsável por apresentar todas as orientações, 
recomendações e determinações para o controle e descarte dos rejeitos sólidos, devendo ser utilizada como norteadora do assunto em todo o país.

De acordo com Costa et al. (2017), a supracitada lei propõe que gestores públicos e da iniciativa privada busquem, de forma efetiva e eficaz, programar ações para a prevenção e diminuição da produção de resíduos. Como resultante, espera-se que tal postura contribua também para que a sociedade em geral tenha ciência da problemática e dos malefícios dela para o meio ambiente, buscando alterar os próprios padrões de consumo que sejam prejudiciais de forma individual e coletivas.

No entanto, segundo Schwemleil (2016; citado por SOUSA et al., 2019), o que se verifica na prática é que os estados e municípios brasileiros, em sua maioria, precisam adequar suas políticas públicas acerca do descarte de Resíduos Sólidos Urbanos, para gerenciar e planejar ações em prol da manutenção e operação do procedimento de forma que reduzam ao máximo todo e qualquer impacto que cause danos ao meio ambiente.

Conforme estudos realizados por Coutinho et al. (2011), Jacobi (2011) e Bessen (2011 (citados por COSTA et al., 2017), os RSU constituem hoje uma das pautas mais importantes na agenda das políticas públicas que trabalham com ações voltadas para o meio ambiente. Tal relevância se deve ao reconhecimento de que a gestão de resíduos sólidos sem planejamento gera impactos ambientais capazes de alterar sobremaneira as condições de vida dos seres vivos (FRATTA et al., 2018).

Deste modo, cada estado ou município tem o dever de analisar e considerar suas situações reais diante do problema, pois cabe às gestões, individualmente, organizar e prestar os serviços públicos pertinentes, tais como os relacionados ao saneamento básico e ao atendimento médico hospitalar de situações oriundas do descarte inadequado. Logo, é preciso ressaltar que é de competência local (estadual e municipal) a prestação dos serviços de gerenciamento de resíduos sólidos de forma direta ou indireta, o que exige de cada cidade a capacidade de formular e gerir ações logísticas específicas para as atividades de coleta, transporte, tratamento e disposição final (FRATTA et al., 2018).

Ainda a este respeito, Silva (2017) pontua que tamanha é a abrangência dos impactos do descarte dos resíduos sólidos que demanda o trabalho de diversos setores, como infraestrutura e saúde pública, entre outros. É bojo deste contexto que aflora o questionamento sobre a relação entre gestão de resíduos sólidos e desenvolvimento sustentável. De acordo com Sousa (2019), há entre elas uma conexão indissociável que torna de suma importância a necessidade delas estarem interligadas no âmbito ambiental, para assim abrir um campo mais amplo de atuação.

O termo Desenvolvimento Sustentável foi formalizado em 1987 pela Comissão Mundial Sobre o Meio Ambiente, sendo apresentado através do Relatório Brundtland por meio de documento intitulado "Nosso Futuro Comum" (tradução livre) (COSTA et al., 2017). De acordo com o citado autor, a finalidade deste documento foi explicar, sucintamente, que o desenvolvimento visto principalmente pelo viés do progresso, não pode ser compreendido somente como uma forma de "satisfazer às necessidades presentes". Assim, preconizou-se que o desenvolvimento não podia ser visto como algo que funciona em progressão geométrica, uma vez que, de modo contrário a isso, os recursos naturais são limitados (COSTA et al., 2017). 
Entretanto, Fratta et al. (2018) explica que ao fazer uma interligação entre desenvolvimento e o que é sustentável, ficou evidente a necessidade de haver uma ligação entre o humano e o meio ambiente. A esse respeito, o autor acrescenta que é indispensável o humano compreender que o sistema ambiental não é estático, e que existe uma propensão do ambiente para absorver os impactos resultantes do uso dos recursos e do próprio crescimento populacional.

Fundamentado em tal entendimento, tem-se a assertiva de para que haja o desenvolvimento sustentável, não pode haver a ausência da gestão ambiental voltada para questões como a do descarte dos resíduos sólidos, pois as ações relativas ao assunto devem ter por essência a busca por alternativas e soluções para resíduos que não causem danos ao ambiente (SILVA, 2017).

Em busca de soluções capazes de contribuírem com o intuito de minimizar os efeitos negativos que o descarte inadequado dos resíduos sólidos causa ao meio ambiente, Silva (2017) salienta que diversos estudiosos sugerem ações para realinhar a matriz energética, dentre as quais a reciclagem, visto que tal prática contribui de fora efetiva com a redução do lixo produzido diariamente. Além disso, o autor diz que por meio da reciclagem é possível romper com o paradoxo do descarte dos resíduos sólidos, permitindo a inclusão da gestão deles para o desenvolvimento sustentável.

Ademais, além de propor e implementar ações, a gestão dos resíduos sólidos deve ser acompanhada e avaliada com o auxílio de indicadores de sustentabilidade, que são mecanismos utilizados para interpretar e mesurar a efetiva situação do descarte dos resíduos sólidos, além das perspectivas referentes à comunidade e entorno envolvidos na questão (FRATTA et al., 2018). Assim, com a crescente produção de resíduos sólidos, a gestão tem função determinante para evitar e eliminar o excesso de dejetos ao meio ambiente, tendo em vista efetivar alternativas que não causem danos ao ambiente (SOUSA, 2019).

\section{MATERIAIS E MÉTODOS}

A base metodológica deste estudo foi o levantamento de literatura específica acerca do tema em destaque, mediante procedimento de buscas nas bases de dados Periódicos CAPES e Google Acadêmico, efetivadas em março de 2020. Para a precisão do refinamento das buscas, foram definidos os seguintes descritores: 'Gestão de Resíduos' AND 'Indicadores de Sustentabilidade' AND 'Desenvolvimento Sustentável' e 'Waste Management' AND 'Sustainability Indicators' AND 'Sustainable Development', utilizados em ambas as bases de dados.

Como resultado, foram selecionados quatro artigos, os quais foram incluídos neste estudo com base nos critérios de elegibilidade pré-estabelecidos, conforme apresentado abaixo (Figura 1). Os critérios de inclusão foram os seguintes: artigos nos idiomas inglês, espanhol e português, publicados nos últimos cinco anos, envolvendo o conhecimento em Gestão de Resíduos Sólidos Urbanos e Desenvolvimento Sustentável. O critério de exclusão foi serem artigos de revisão de literatura. 


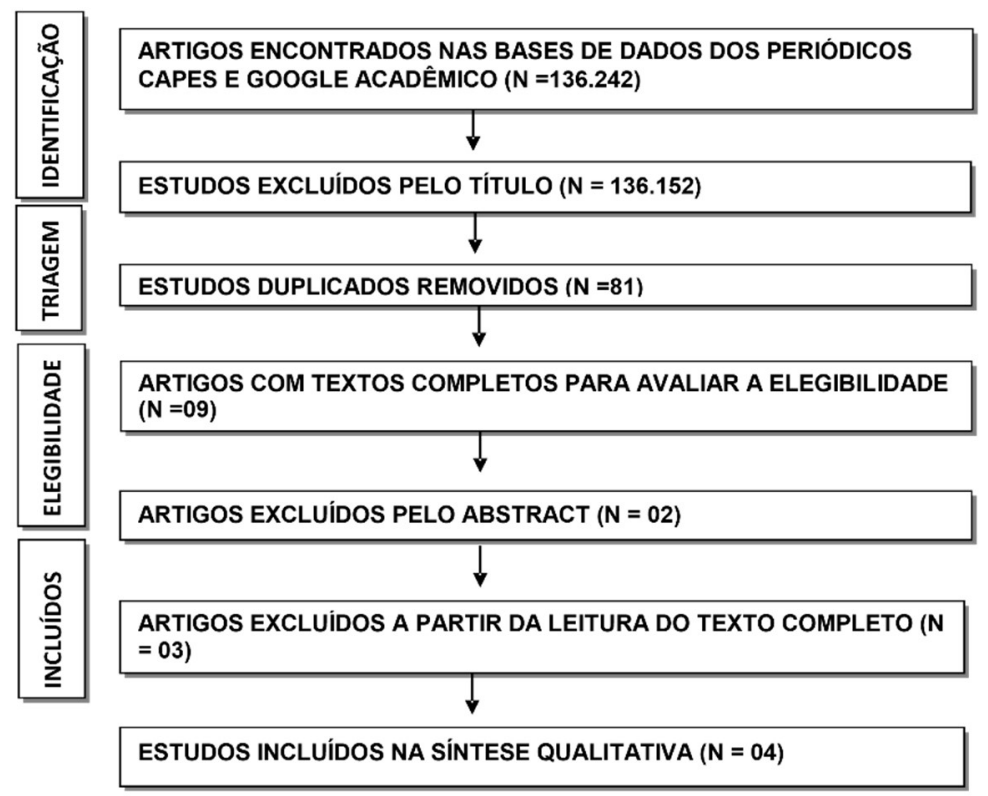

\section{RESULTADOS}

Figura 1: Fluxograma e critérios de seleção e inclusão dos artigos.

$\mathrm{Na}$ apresentação dos resultados obtidos pela fundamentação teórica que compõe este artigo, são apresentados os principais elementos dos quatro textos incluídos nesta síntese qualitativa, a saber: data de publicação; autoria; local da publicação; objetivos propostos e resultados obtidos.

Para a melhor organização de tais informações, os resultados do presente estudo foram organizados na Tabela 1, apresentada abaixo.

Tabela 1: Demonstrativo dos artigos que integram a revisão.

\begin{tabular}{|c|c|c|c|c|c|}
\hline Data & Título & Autores & Periódico & Objetivos & Resultados \\
\hline 2019 & $\begin{array}{l}\text { Indicadores } \\
\text { ambientais de } \\
\text { resíduos sólidos } \\
\text { urbanos associados à } \\
\text { melhoria das } \\
\text { políticas públicas }\end{array}$ & $\begin{array}{l}\text { Mikaely da } \\
\text { Silva Souza; } \\
\text { Juan Carlos } \\
\text { Valdes Serra. }\end{array}$ & $\begin{array}{l}\text { Revista Gestão e } \\
\text { Sustentabilidade }\end{array}$ & $\begin{array}{llr}\text { Abordar a temática } \\
\text { Gestão de } & \text { resíduos } \\
\text { sólidos } & \text { e } & \\
\text { desenvolvimento } \\
\text { sustentável. }\end{array}$ & $\begin{array}{l}\text { A adoção das tecnologias de } \\
\text { informação e comunicação é } \\
\text { também um dos mecanismos } \\
\text { que pode ampliar a } \\
\text { efetividade das políticas } \\
\text { públicas em torno da gestão } \\
\text { de resíduos sólidos. Além de } \\
\text { proporcionar transparência } \\
\text { pública, a divulgação de } \\
\text { informações torna o cidadão } \\
\text { mais sensibilizado e ciente do } \\
\text { seu papel como gerador de } \\
\text { resíduos que deve atuar no } \\
\text { ciclo de responsabilidade } \\
\text { compartilhada definida pela } \\
\text { PNRS (Política Nacional dos } \\
\text { Resíduos Sólidos). }\end{array}$ \\
\hline 2018 & $\begin{array}{l}\text { Diagnóstico da } \\
\text { gestão de resíduos } \\
\text { urbanos sólidos dos } \\
\text { municípios do } A B C \\
\text { Paulista do Brasil } \\
\text { através da aplicação } \\
\text { de indicadores de } \\
\text { sustentabilidade. }\end{array}$ & $\begin{array}{l}\text { Kelly Danielly } \\
\text { da Silva } \\
\text { Alcantara } \\
\text { Fratta; } \\
\text { Juliana } \\
\text { Tófano de } \\
\text { Campos Leite } \\
\text { Toneli; } \\
\text { Graziella } \\
\text { Colato } \\
\text { Antonio. }\end{array}$ & $\begin{array}{l}\text { International Journal } \\
\text { for Scientific } \\
\text { Research into the } \\
\text { Environment and its } \\
\text { Relationship with } \\
\text { Hunankind }\end{array}$ & $\begin{array}{l}\text { Abordar a discussão } \\
\text { sobre os princípios da } \\
\text { sustentabilidade na } \\
\text { gestão dos resíduos } \\
\text { sólidos, além de } \\
\text { analisar a Política } \\
\text { Nacional de Resíduos } \\
\text { Sólidos à luz do } \\
\text { pensamento } \\
\text { sistêmico. }\end{array}$ & $\begin{array}{l}\text { A combinação de todas essas } \\
\text { etapas visa formar um ideal } \\
\text { cenário para o uso de RSU } \\
\text { (Resíduos Sólidos Urbanos), } \\
\text { levando em consideração a } \\
\text { necessidade de } \\
\text { monitoramento constante e a } \\
\text { possibilidade de aplicar os } \\
\text { indicadores, que servirá para } \\
\text { ajustar e adaptar-se à } \\
\text { qualidade dos resquícios } \\
\text { urbanos. }\end{array}$ \\
\hline
\end{tabular}




\begin{tabular}{|c|c|c|c|c|c|}
\hline 2017 & $\begin{array}{l}\text { Indicadores da } \\
\text { gestão de resíduos } \\
\text { sólidos urbano: uma } \\
\text { visão voltada à } \\
\text { sustentabilidade. }\end{array}$ & $\begin{array}{l}\text { Luciana da } \\
\text { Silva }\end{array}$ & $\begin{array}{lr}\text { Dissertação } \\
\text { apresentada } \\
\text { Programa de } & \text { Pós- } \\
\text { Graduação } & \text { em } \\
\text { Engenharia } & \text { Civil da } \\
\text { Faculdade } & \text { de } \\
\text { Engenharia } & \text { e } \\
\text { Arquitetura } & \text { da } \\
\text { Universidade } & \text { de } \\
\text { Passo Fundo. } & \end{array}$ & $\begin{array}{l}\text { Abordar a importância } \\
\text { da Gestão de Resíduos } \\
\text { sólidos } \\
\text { desenvolvimento } \\
\text { sustentável. }\end{array}$ & $\begin{array}{l}\text { A urgente necessidade de } \\
\text { aprimoramento das bases de } \\
\text { dados municipais com } \\
\text { incremento de indicadores de } \\
\text { sustentabilidade da GRSU } \\
\text { (Gestão de Resíduos Sólidos } \\
\text { Urbanos), principalmente nos } \\
\text { municípios de médio porte } \\
\text { que apresentam as maiores } \\
\text { taxas de crescimento entre as } \\
\text { cidades brasileiras. }\end{array}$ \\
\hline 2017 & $\begin{array}{l}\text { Os princípios da } \\
\text { sustentabilidade } \\
\text { como norteadores na } \\
\text { gestão dos resíduos } \\
\text { sólidos urbanos. }\end{array}$ & $\begin{array}{l}\text { Amanda } \\
\text { Rodrigues } \\
\text { Santos } \\
\text { Costal; Sara } \\
\text { Maria Gomes } \\
\text { Pinheiro; } \\
\text { Alcione } \\
\text { Moraes de } \\
\text { Melo; Soraya } \\
\text { Giovanetti El- } \\
\text { Dierl. }\end{array}$ & $\begin{array}{ll}\text { Revista } & \text { Holos } \\
\text { Environment } & \end{array}$ & $\begin{array}{l}\text { Abordar a Gestão de } \\
\text { resíduos sólidos e o } \\
\text { desenvolvimento } \\
\text { sustentável. }\end{array}$ & $\begin{array}{l}\text { O descarte direto de resíduos } \\
\text { em canais ou rios provoca a } \\
\text { contaminação da água e o } \\
\text { assoreamento; a disposição } \\
\text { na rua e em calçadas, no } \\
\text { entupimento de bueiros, com } \\
\text { consequente aumento das } \\
\text { enchentes em épocas de } \\
\text { chuva. O risco ocorre quando } \\
\text { a água contaminada é usada } \\
\text { para abastecimento ou para } \\
\text { irrigação, demonstrando que } \\
\text { o problema não é pontual, ao } \\
\text { contrário, levando a sentir os } \\
\text { efeitos do problema para } \\
\text { locais distantes da origem. } \\
\text { Evidencia-se, desse modo, a } \\
\text { inter-relação entre os } \\
\text { elementos de um sistema } \\
\text { urbano, de maneira que um } \\
\text { não pode ser gerido } \\
\text { isoladamente ao outro. Tal } \\
\text { fato demonstra a necessidade } \\
\text { da abordagem sistêmica } \\
\text { quando se trata da gestão e do } \\
\text { gerenciamento dos resíduos. }\end{array}$ \\
\hline
\end{tabular}

\section{DISCUSSÃO}

O objetivo do presente estudo foi destacar o conhecimento produzido cientificamente a respeito da Gestão de Resíduos Sólidos Urbanos e a relação existente com o desenvolvimento sustentável. Abordagem que nos conduz a repensar toda a cadeia referente ao descarte de resíduos, sejam eles oriundo da produção de materiais industrializados, domésticos, hospitalares entre outros.

Evidenciou-se a partir das análises que é evidente a necessidade de os gestores públicos e privados darem um destino final adequado aos resíduos sólidos, sendo destacado que no Brasil, por meio da legislação nacional, o Plano Nacional de Resíduos Sólidos corresponde ao conjunto de normas que regem desde a produção dos dejetos, gestão, logística e destinação. Assim, todo o processo deve ser planejado de acordo com o referido documento legal (SILVA, 2017).

O Congresso Nacional sancionou a Lei da Política de Resíduos Sólidos, art.1ํ da Lei 12.305, de 2 de agosto de 2010, com o objetivo de criar diretrizes e mecanismos para o controle dos resíduos sólidos, como também estabelecer as bases legais, com validade em todo o território nacional, voltadas para ações integradas e planejadas acerca do descarte e reutilização desse material.

A este respeito, estudo conduzido por Santos et al. (2017; citado por SOUSA et al., 2019), apresenta resultados que indicam que um dos maiores problemas referentes à preservação do meio ambiente está 
relacionados justamente com questões que envolvem a produção, o acúmulo e o destino que é dado para os resíduos sólidos.

Assim, a partir da supracitada lei, passou-se a ter de forma estabelecida no Brasil, "o conjunto de princípios, objetivos, instrumentos, diretrizes, metas e ações adotados pelo Governo Federal, isoladamente ou em regime de cooperação com Estados, Distrito Federal, Municípios ou particulares, com vistas à gestão integrada e ao gerenciamento ambientalmente adequado dos resíduos sólidos" (BRASIL, 2010).

O fato é que planos e programas de gestão ambiental são ferramentas imprescindíveis para todo e qualquer planejamento ambiental, devendo ser estabelecido e exigido por lei. É importante salientar, que planos como os ambientais nada mais são do que um conjunto de medidas com diretrizes para ações e resultados de curto, médio e longo prazo, e que devem ser colocadas em prática com o objetivo de continuidade e constante atualização.

Além disso, a condução, o direcionamento e a proteção do meio ambiente dependem de uma gestão ambiental normatizada, em que a responsabilidade pela preservação dos recursos naturais e do bem comum sejam de responsabilidade de toda a sociedade, não cabendo somente aos governos e aos gestores de grandes organizações, o dever de assumirem posturas proativas a este respeito (SOUZA, 2019).

Portanto, como ressaltam Costa et al. (2017), as esferas governamentais e empresariais devem ser apoiadas por toda a sociedade civil na busca por alternativas que sejam não apenas paliativas, mas que sejam de fato efetivas na adoção de meios para a redução dos impactos que o descarte inadequado de resíduos causa ao ambiente.

Desse modo, a Gestão Integrada para o Desenvolvimento Sustentável (BRASIL, 2010) representa a compilação de um apanhado de propósitos, formulados com embasamento científico, econômico e social, que tem como finalidade contribuir para que os estados e municípios brasileiros atuem com vistas para minimizar a geração de resíduos. Ou seja, para que as ações resultem na diminuição dos impactos ambientais, tais como por meio de uma maximização da reutilização.

Ainda no âmbito legal, Silva (2017) mostra através de seu estudo, que é evidente a necessidade de que todo o país adote de forma integral os preceitos da política de Resíduos Sólidos do Brasil (lei no 12.305), mais precisamente o art.7으, que propõe a "adoção, desenvolvimento e aprimoramento de tecnologias limpas como forma de minimizar impactos ambientais" (BRASIL, 2010).

Conforme Silva (2017), a definição de gestão integrada de resíduos deve ser adotada como sendo fundamental para o desenvolvimento de ações relativas aos resíduos sólidos. Para ele, a partir de então a busca por soluções deve estar sempre alinhada com a premissa do desenvolvimento sustentável, ou seja, considerando os vários setores sociais, ambientais e econômicos que estejam direta ou indiretamente envolvidos na situação em foco.

Nesse sentido, Fratta et al. (2018) destaca que as metas estabelecidas para a gestão de resíduos urbanos precisam levar em consideração as diferentes realidades das cidades, pois, para serem cumpridas, é fundamental a participação, gerenciamento e planejamento que contemplem as reais demandas e 
condições de trabalho. É neste contexto que a coleta seletiva desponta como uma viável para que, de maneira geral, os gestores possam dar um destino menos nocivo aos resíduos das cidades.

Para Silva (2017), a coleta seletiva é uma ação que pode ser considerada de fácil execução e que envolve baixos custos. Assim, sua adoção se torna fácil e viável em larga escala, sendo uma atividade que contribui de forma positiva com o meio ambiente e que estimula a sustentabilidade não apenas ambiental como também social e econômica. Além disso, a Lei Federal 12.305/2010 estabelece a implantação e o aprimoramento da coleta seletiva em todos os municípios brasileiros, embora na prática essa ação não seja uma realidade (SILVA, 2017).

A esse respeito, Cifrian et al. (2015; citado por SILVA, 2017) comenta sobre o estudo e execução das metas que estão relacionadas principalmente ao sucesso da implantação dos sistemas de coleta seletiva pelo município e de logística reversa, conforme instituído no PNRS (Plano Nacional dos Resíduos Sólidos).

Ainda no âmbito das iniciativas sugeridas com o intuito de melhorar as atividades relacionadas ao gerenciamento de RSU (Resíduos Sólidos Urbanos) sustentável, estudos de Silva (2017) salientam a importância dos sistemas de indicadores, ferramentas que contribuem para a obtenção de dados com qualidade e precisão acerca da realidade vivenciada. Para o referido autor, "a obtenção desses resultados é uma questão fundamental para o processo de projetar ou elaborar um sistema de indicadores, uma vez que os indicadores devem ser relevantes, ter credibilidade, ser funcionais, ser quantificáveis, e ter comparabilidade (SILVA, 2017). No que se referente aos resíduos sólidos urbanos, esse indicador deverá verificar o impacto parcial e total do descarte real, ou seja, tanto do realizado de forma adequada, quanto o que é feito inadequadamente, sendo que esse último tem maior relevância, pois apresenta as condições do ambiente e mensura o quanto ele ainda é capaz de suportar, caso continue sofrendo com tal impacto.

Sendo assim, Sousa (2019) destaque que no ano de 2014, a norma internacional ISO (International Organization for Standardization), publicou a ISO 37120, documento que "apresenta um conjunto de indicadores para medir o desempenho da prestação de serviços e a qualidade de vida nas cidades, através dos aspectos sociais, ambientais e econômicos" (SOUSA et al., 2019).

Assim como tudo que envolve a gestão de resíduos sólidos, também é preciso compreender que existem diferentes modelos de indicadores de sustentabilidade, o que exige análise prévia para identificar quais de fato irão auxiliar no processo de desenvolvimento sustentável de cada realidade (COSTA et al., 2017). Deste modo, faz-se imprescindível que os gestores planejam as ações considerando uma visão abrangente do assunto, e não apenas uma iniciativa com práticas, alcances e resultados parciais.

Conforme Silva (2017), os indicadores de sustentabilidade devem ser vistos como parâmetros que irão apresentar informações sobre a situação. Entre os mais comumente utilizados, estudos feitos por Costa et al. (2017) citam a Pegada Ecológica, o Índice de Sustentabilidade Ambiental (ISA) e a Pegada de Carbono:

Os indicadores de sustentabilidade são ferramentas que auxiliam no monitoramento da operacionalização do desenvolvimento sustentável, tendo como função principal fornecer informações sobre o estado das diversas dimensões que o compõe são exemplos de indicadores de sustentabilidade a Pegada Ecológica, o Painel da Sustentabilidade, o Índice de Sustentabilidade Ambiental (ISA), o Índice de Desenvolvimento Humano (IDH), a Pegada de Carbono, dentre outros parâmetros (COSTA et al., 2017). O fato é que conforme 
apresentado nesta discussão teórica, para que sejam efetivos, os sistemas de planejamento, o uso de indicadores de sustentabilidade e gerenciamento integrado de resíduos, devem ser ações operacionalizadas de forma interligada entre as políticas públicas, condutas de gestão privadas e práticas socioculturais. Procurando acompanhar o paradigma holístico, a gestão dos resíduos sólidos urbanos tem evoluído em busca de uma visão sistêmica, promovendo a ideia de um sistema aberto no qual todos os atores - sociedade, governo, empresas privadas, organizações não governamentais interagem em todas as etapas de gerenciamento e são corresponsáveis pelo sucesso delas (COSTA et al., 2017).

Por conseguinte, faz-se evidente que a gestão de resíduos sólidos urbanos demanda mais do que ações pontuais, sem planejamento prévio, organizadas e operacionalizadas por setores isolados, e sem que sejam consideradas as especificidades de cada ambiente e sociedade envolvida. É somente por meio de um esquema de gestão comprometido que os resíduos sólidos urbanos deixarão de ser um grave problema ambiental, social e econômico (COSTA et al., 2017).

\section{CONCLUSÕES}

Foram salientados nesse artigo pesquisas que problematizaram a relação entre a Gestão de Resíduos Sólidos e o Desenvolvimento Sustentável, destacando a relevância da Política Nacional de Resíduos Sólidos (PNR), na condição de parâmetro legal que norteia a questão em todo o território nacional. Conforme foi evidenciado, a política dos resíduos sólidos busca alternativas sustentáveis desde a produção até o momento da dispersão dos materiais produzidos tanto no ambiente doméstico, como também no industrial, ou seja, abrangendo a sociedade em geral.

Desse modo, a Política Nacional de Resíduos Sólidos apresenta as principais diretrizes para a gestão e o planejamento de RSU. É ela a base para nortear estados e municípios sobre o uso e descarte dos resíduos produzidos no país, independente da origem deles. Aos territórios (municípios e estados) cabe o dever de planejar e gerenciar o descarte dos próprios resíduos, criando através de suas políticas públicas, meios e mecanismos adequados para a realidade vivenciada, tendo em vista práticas que contribuam para o desenvolvimento social sustentável.

Nesse sentido, outro fator de relevância é o uso dos indicadores de sustentabilidade, pois eles buscam analisar os sistemas de gestão de resíduos de forma mais geral, e não apenas de modo parcial. Contudo, para uma aplicação mais efetiva e com resultados satisfatórios, os indicadores precisam ser usados de forma sistemática. Além disso, também foi ressalto neste apanhado teórico, que a avaliação da gestão dos resíduos sólidos urbanos mediante a utilização dos indicadores enquanto ferramenta para a análise dos dados e criação de planos de execução deve estar comprometida com as questões ambientais, além de ser eficiente e estar alinhada com a Política Nacional dos Resíduos Sólidos.

Faz-se pertinente salientar que a gestão de resíduos sólidos deve ter como fundamento básico extinguir ou amenizar o processo de degradação ambiental, problemática eminente resultante do descarte inadequado. Nesse sentido, reitera-se que o sistema gerenciamento se fundamenta em parcerias entre as políticas públicas setoriais e ações que coloquem em prática a Lei dos Resíduos Sólidos (12.305 de 2010). 
Embora o desenvolvimento sustentável tenha ganhado destaque nos últimos anos, haja vista a relevância da busca por ações que minimizem os danos ambientais causados por diversos setores produtivos e sociais, assumir a sustentabilidade como pilar principal nas práticas de gestão de resíduos sólidos em busca do desenvolvimento sustentável requer mais do que o mero reconhecimento. Para além disso, é urgente reconhecer a participação compartilhada de gestores públicos e privados, bem como da sociedade como um todo.

\section{REFERÊNCIAS}

BRASIL. Lei. 12.305, de 2 de agosto de 2010. Instituiu a Política Nacional de Resíduos Sólidos; altera a lei n. 9.605, de 12 de fevereiro de 1998, e das outras providências. Brasília: DOU, 2010.

CONAMA. Conselho Nacional do Meio Ambiente. Resolução de n. 5, de 5 de agosto de 1993. Publicada no DOU n. 166, de 31 de agosto de 1993, seção 1, páginas 12996-12998. Brasília: CONAMA, 1993.

COSTA, A. R. S.; PINHEIRO, S. M. G.; MELO, A. M.; EL-DEIR, S. G.. Os princípios da sustentabilidade como norteadores na gestão dos resíduos sólidos urbanos. Revista Holos Environment, Recife, v.17, n.1, p. 94-109, 2017.
FRATTA, K. D. S. A.; TONELI, J. T. C. L.; COLATO, A. G.. Diagnóstico da gestão de resíduos urbanos sólidos dos municípios do $A B C$ paulista do brasil através da aplicação de indicadores de sustentabilidade. Revista Elsevier L.T.D, Santo André, v.85, n.1, p.11-17, 2018.

SILVA, L.. Indicadores de gestão de resíduos sólidos urbanos: uma visão voltada à sustentabilidade. Dissertação (Mestrado) - Universidade de Passo Fundo, São José, 2017. SOUSA, M. S.. Indicadores ambientais de resíduos sólidos urbanos associados a melhoria das políticas públicas. Revista Gestão \& Sustentabilidade, Florianópolis, v.8, n.3, p.707724, 2019.

A CBPC - Companhia Brasileira de Produção Científica (CNPJ: 11.221.422/0001-03) detém os direitos materiais desta publicação. Os direitos referem-se à publicação do trabalho em qualquer parte do mundo, incluindo os direitos às renovações, expansões e disseminações da contribuição, bem como outros direitos subsidiários. Todos os trabalhos publicados eletronicamente poderão posteriormente ser publicados em coletâneas impressas sob coordenação da Cognitionis Publishing, da Companhia Brasileira de Produção Científica e seus parceiros autorizados. Os (as) autores (as) preservam os direitos autorais, mas não têm permissão para a publicação da contribuição em outro meio, impresso ou digital, em português ou em tradução. 